\title{
Polyacrylamide hydrogel application in sand control with compressive strength testing
}

\author{
Mahsa Baghban Salehi $^{1} \cdot$ Asefe Mousavi Moghadam ${ }^{1} \cdot$ Samira Zargari Marandi $^{2}$
}

Received: 1 April 2018/Published online: 4 September 2018

(C) The Author(s) 2018

\begin{abstract}
Sand production is one of the major problems in sandstone reservoirs. Different mechanical and chemical methods have been proposed to control sand production. In this paper, we propose a chemical method based on using polyacrylamide/ chromium triacetate hydrogel to investigate sand production in a synthetic sandpack system. To this end, a series of bulk experiments including the bottle test and rheological analysis along with compression tests were conducted. Experimental results indicated that the compressive strength of the sandpack was increased as much as 30 times by injecting 0.5 pore volume of hydrogel. Also, it was found that the increases in cross-linker and polymer concentrations exhibited a positive impact on the compressive strength of the sandpack, mostly by cross-linker concentration (48 psi). Hydrogel with a higher value of cross-linker could retain its viscoelastic properties against the strain which was a maximum of $122 \%$ for 0.5 weight ratio of cross-linker/polymer. The presence of salts, in particular divalent cations, has a detrimental effect on the hydrogel stability. The maximum strain value applied on hydrogel in the presence of $\mathrm{CaCl}_{2}$ was only about $201 \%$ as compared to $1010 \%$ in the presence of distilled water. Finally, thermogravimetric analysis and its derivative showed that the hydrogel could retain its structure up to $300{ }^{\circ} \mathrm{C}$. The results of this study revealed the potential application of the hydrogel to control sand production.
\end{abstract}

Keywords Sand control $\cdot$ Rheology $\cdot$ Hydrogel strength $\cdot$ Compressive strength $\cdot$ Sandpack

\section{Introduction}

Sand production is one of the common problems in oil and gas production wells drilled in unconsolidated formations (Fattahpour et al. 2012). The abrasive flow of sand grains inside the wells and production lines leads to undesirable consequences including erosion of downhole or wellhead equipment, clogging of downhole equipment, subsidence of formation rock, walls destruction, reduction in reservoir recovery, maintenance cost, and in severe cases even death of the well (Ikporo and Sylvester 2015; Isehunwa and

Edited by Yan-Hua Sun

Mahsa Baghban Salehi

m.bsalehi@ccerci.ac.ir

1 Department of Petroleum Engineering, Chemistry and Chemical Engineering Research Center of Iran, Tehran 14335-186, Iran

2 Faculty of Chemical Engineering, Tarbiat Modares University, Tehran 14115-143, Iran
Olanrewaju 2010; Pedersen et al. 2017; Singh and van Petegem 2014). Sand production begins when the imposed in situ stresses on the formation exceeds the in situ formation strength (Gholami et al. 2016). On the contrary, sand consolidation usually happens when the natural bonds attach the grains by the cement materials in formations (Marfo et al. 2015).

There are several mechanical methods to reduce sand production such as screens, slotted liners, expandable sand screens (Cholet 2000), and improvement of the perforating operation during the well completion. However, mechanical methods are often time-consuming and costly in the production process (Kotlar et al. 2008). Chemical methods are an alternative method for a poorly consolidated formation that produces a lot of sand (Kotlar et al. 2005). These methods were implemented based on the injection of chemical components around the wellhead to consolidate the formation rock to reduce the further movement of sand grains (Maduabuchi et al. 2017).

In general, chemical methods have been divided into two groups (Bellarby 2009: (1) application of resin-coated 
gravels as a downhole filter (screen-free), and (2) in situ consolidation by injection of compatible fluid and artificial attachment of sand grains near the wellbore. For this purpose, the fluid is injected into the formation pores through the perforations which hardens after coating the sand grains and reduces excess sand movement during the production operation. In this approach, fluid injection must be implemented at the desired time at which the production rate exceeds a critical value (Bellarby 2009). Besides, the chemical method can be carried out in two ways: by oxidation of a hydrocarbon material that saturates the sand around the wellbore (Aggour and Abu-Khamsin 2004) and injection of polymeric or non-polymeric components into the formation rock (El-Sayed et al. 2001; Kotlar et al. 2005, 2008; Wasnik et al. 2005).

Resins mostly are applied in sand control studies in which, in those cases, liquid polymeric resins have the ability to change phase to solid (Marfo et al. 2015). Although resins are frequently used as a consolidation fluid in chemical methods, application of these materials is unpleasant under environmental and economic perspectives, due to their tendency to reduce the formation permeability (Sydansk 1992). In the case of operational feasibility, resins could not be easily embedded in the formation rock. Improper and unsafe aspects of fluid caused by acids and solvents as well as problems such as the application of surface equipment and pumping systems are among the other constraints of using resin materials (Villesca et al. 2010). Regarding the limited time of pumping, injection of highly viscous resin solutions into the formation leads to unsatisfactory operation of the formations with permeability less than $50 \mathrm{mD}$ (Sydansk 1988). Therefore, it is essential to use consolidating materials, which are environmentally friendly and costeffective, to control sand production.

According to the previous studies, one could imagine the potential application of hydrogel to remedy sand production compared to other chemical methods mainly due to its lower required concentration, adjustable viscosity, and good injectivity (Bai et al. 2015; Karimi et al. 2014). Hydrogels are formed by mixing a polymer solution with an appropriate cross-linker solution at a specific temperate (Baghban Salehi et al. 2014; Li et al. 2007).

Besides, the formation strength is one main factor that must be considered when investigating sand control mechanisms. To this end, one could perform a uniaxial compression analysis to obtain the highest stress that the sand formation can tolerate during the compression process (Mishra and Ojha 2016a, b). When one exceeds the highest stress, the sand formation loses its mechanical strength and sand grains start moving by fluid flow. In the previous studies, the magnitude of the compressive strength was used to evaluate sand consolidation in which the higher the compressive strength, the more stable the sands (Mishra and Ojha 2016b). We also measured the compressive strengths of sand samples after hydrogel injection.

In this study, we used polyacrylamide as polymer and chromium triacetate as the cross-linking agent to generate hydrogel as a sand consolidation agent. To this end, the hydrogel's strength and its composition effect on the compressive strength of the sandpack were investigated to indicate whether the sand consolidation might be increased by hydrogel and the hydrogel strength would be effective in sand control or the hydrogel structure might be independent of its strength in increasing the compressive strength of sand. Therefore, a set of experiments including bottle tests, rheological analyses and compression tests along with thermogravimetric analysis (TGA) were performed. Also, the effect of mono and divalent cations and temperature on the hydrogel stability was studied.

\section{Experimental}

\subsection{Materials}

Hydrolyzed acrylamido propyl sulfonated acid (polyacrylamide polymer sodium salt, trade name of AN125, molecular weight $(\mathrm{MW})$ of $8.0 \times 10^{6}$, sulfonation degree of $25 \%$, and water content of $<10 \mathrm{wt} \%$ ) was purchased from SNF Co. (Saint-Étienne, France). Chromium triacetate, $\mathrm{Cr}(\mathrm{OAc})_{3}$, (Carlo Erba Co., Italy) was used in powder form as a cross-linker. Distilled water was used as a solvent for preparation of hydrogels. $\mathrm{NaCl}, \mathrm{KCl}$, $\mathrm{CaCl}_{2} \cdot 2 \mathrm{H}_{2} \mathrm{O}$, and $\mathrm{MgCl}_{2} \cdot 2 \mathrm{H}_{2} \mathrm{O}$ (Merck, Germany) were used to prepare synthetic formation water based on the composition of actual formation water of one of the Iranian reservoirs and to study the effect of mono and divalent ions.

\subsection{Synthesis of hydrogel}

In this work, sulfonated polyacrylamide cross-linked with $\mathrm{Cr}(\mathrm{OAc})_{3}$ was mixed at room temperature to prepare the gelant solution which becomes gel at a defined time and temperature. Firstly, an aqueous solution of polymer was mixed for $24 \mathrm{~h}$ to ensure a complete homogeneous solution using an overhead stirrer (HS-30D, Daihan Scientific Co., Korea). Thereafter, a cross-linker solution was prepared by adding $\mathrm{Cr}(\mathrm{OAc})_{3}$ to distilled water and then stirred at room temperature for $5 \mathrm{~min}$ using a magnetic stirrer (Stuart CB162, UK). Then, the gelant solution was prepared by mixing the polymer and the cross-linker solutions for 10 min. It must be noted that most of the south Iranian reservoirs have high reservoir temperature, around $90{ }^{\circ} \mathrm{C}$; therefore, all experiments in this study were performed at $90{ }^{\circ} \mathrm{C}$. A set of experiments, as shown in Fig. 1, were 


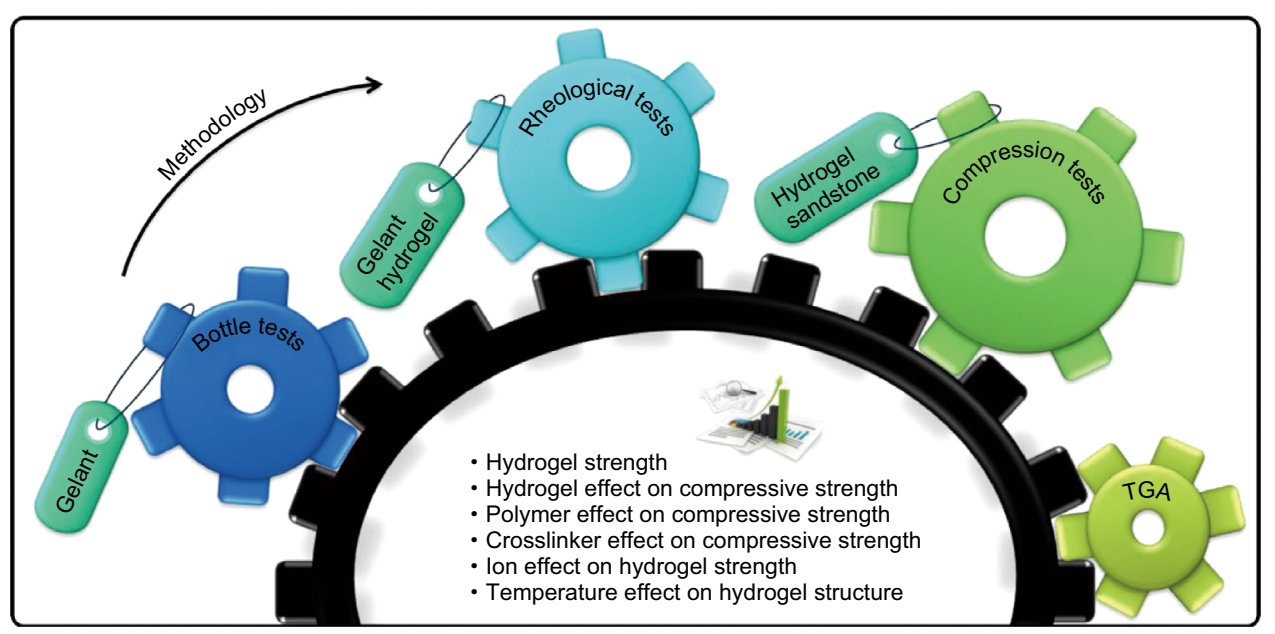

Fig. 1 Schematic diagram of experimental steps

designed and carried out to investigate the strength of hydrogels with desirable composition in sand control.

\subsection{Bottle tests}

In the bottle test, the time of hydrogel formation (gelation time) is measured, while the hydrogel is not under stress or shear (Akhlaghi Amiri and Hamouda 2014; Salimi et al. 2014). Generally, the bottle test is a simple and fast method to evaluate the gelation time, gel strength, heat resistance, syneresis time (Karimi et al. 2016; Li et al. 2016), and to determine the hydrogel composition of cross-linker and polymer (Adewunmi et al. 2017). The samples were transferred into high thermal resistance glass tubes $(70 \mathrm{~mL}$, Simax, Italy) and were kept at $90{ }^{\circ} \mathrm{C}$ in an UN55 oven (Memmert, Germany). The glass tubes were inverted at various time intervals, and the corresponding gel properties were recorded under the influence of gravity. The hydrogel strength was determined as alphabetical codes of A, B, C, D, E, (fluid hydrogel) F, G, H, (non-fluid hydrogel), I, and J (rigid gel) (Karimi et al. 2014; Sydansk and Argabright 1987). Code $\mathrm{H}$ was selected in this research as a desired hydrogel because of its suitable strength and stability.

\subsection{Rheological tests}

The viscoelastic behavior of a polymeric system is best shown when a periodic shear strain is applied to it (periodic regimes) (Yanovsky 1993). In this case, $\gamma_{i} \propto \exp (-i w t)$, where $\omega$ is the angular frequency of deformation. The storage modulus, $G^{\prime}$, and loss modulus, $G^{\prime \prime}$, are experimentally measured to illustrate the dynamic viscoelastic properties of the polymeric system (Salimi et al. 2014). They are real and imaginary parts of the complex dynamic modulus (Liu and Seright 2000; Mousavi Moghadam et al. 2014):

$$
\left|G^{*}(\omega)\right|=\left|G^{\prime 2}(\omega)+G^{2}(\omega)\right|^{0.5}
$$

The ratio of loss modulus to storage modulus is referred to as loss factor or loss tangent:

$\tan \delta=G^{\prime \prime} / G^{\prime}$

In an elastic solid, $\delta=0$ or $\tan \delta=0$ as $G^{\prime}$ dominates $G^{\prime \prime}$ completely. However, in a viscous fluid, $\delta=90^{\circ}$ or $\tan \delta=$ $\infty$ as $G^{\prime \prime}$ dominates $G^{\prime}$ completely. In viscoelastic materials, $0 \leq \tan \delta \leq \infty$ depends on the timescale and temperature. When the viscous and elastic behavior is equal, $\delta=45^{\circ}$ or $\tan \delta=1$, the material is making a transition from liquid to solid or vice versa (Osswald and Rudolph 2015). A MCR501 rheometer (Anton Paar, Austria) was used to evaluate the hydrogel strength. Using parallel-plate sensor systems has an additional advantage of the relative ease of removing the cured platelike sample from the sensor system. So, storage and loss moduli were measured using a parallel-plate rheometer (diameter of $50 \mathrm{~mm}$ with a 3-mm gap) in the linear strain domain, with an applied strain amplitude of $1 \%$. The frequency was from 0.1 to $100 \mathrm{~Hz}$ at $90{ }^{\circ} \mathrm{C}$. The above equations were considered as the key factors for studying the rheological behavior of hydrogels. It should be noted that these parameters were varied while transferring the gelant solution to a gel.

\subsection{Compression tests}

The compression tests were carried out in three main steps: sandpack preparation, hydrogel injection, and compressive strength measurement. Figure 2 shows a complete schematic of this process. 


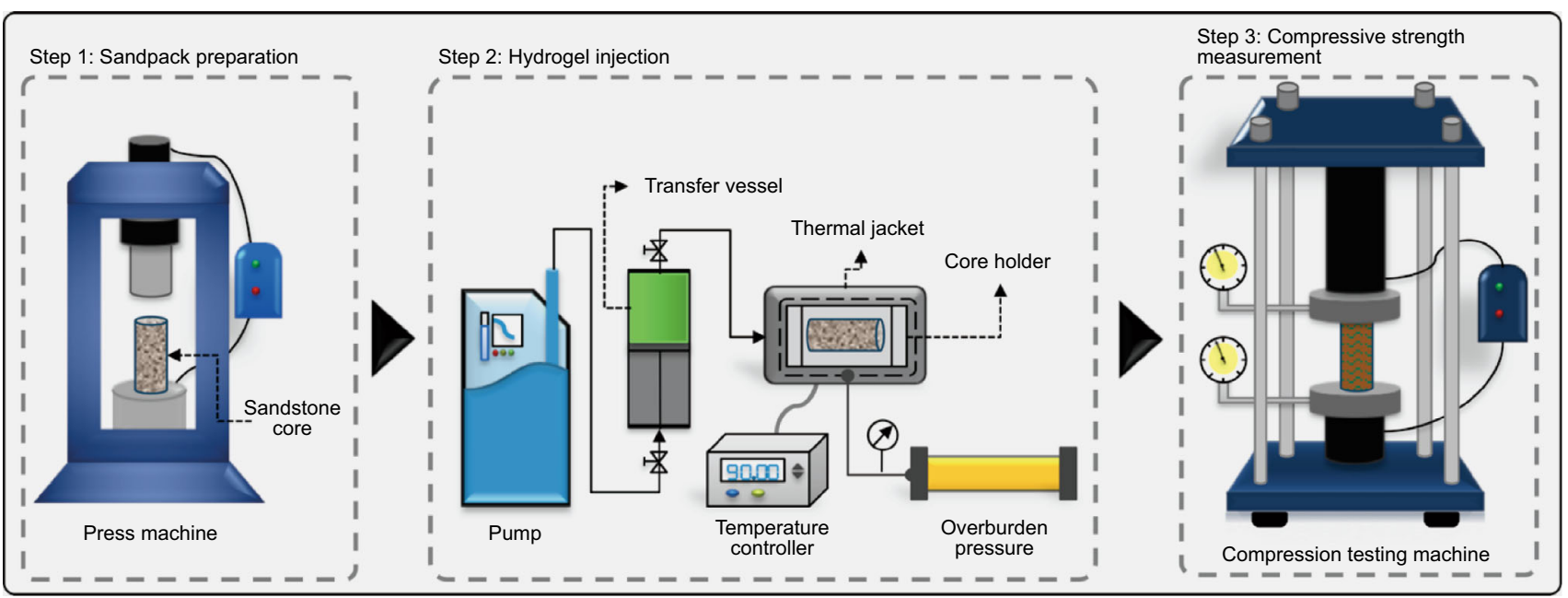

Fig. 2 Schematic of the compression test process

\subsubsection{Sandpack preparation}

An important issue in this research was the preparation of suitable sandstone cores for experiments because of the importance of their initial strength and similarity of their strength. Sandpack was prepared based on grain size analysis (60-1000 $\mu \mathrm{m})$ of one Iranian reservoir with a sand production problem. The real sandstone core was pulverized and used for sandpack preparation with the same sand grain size. The grain size distribution is shown in Fig. 3. For this purpose, sandpacks of $3.81 \mathrm{~cm}$ (1.5 in.) diameter and $7.62 \mathrm{~cm}$ (3.0 in.) length were pressed with a press machine (Shahab Machine Co., Iran) under 2 bar pressure for $10 \mathrm{~min}$ and then dried at $90{ }^{\circ} \mathrm{C}$. These values were kept constant during this step for all the samples.

\subsubsection{Hydrogel injection}

Generally, the hydrogel injection setup has different parts (Bravo and Araujo 2008). Its main part is a core holder, thermal jacket, temperature controller $\left(120{ }^{\circ} \mathrm{C}\right.$ with $1{ }^{\circ} \mathrm{C}$ accuracy), injection pumps (0.01-32 mL/min and $600 \mathrm{bar}$ ),

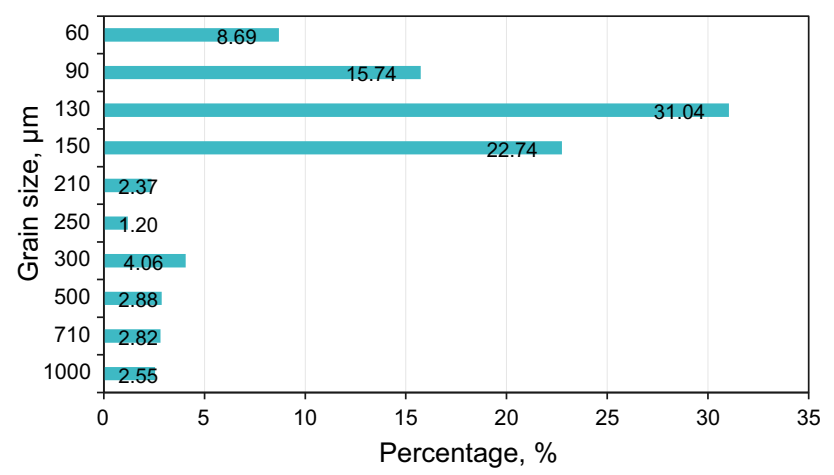

Fig. 3 Grain size distribution overburden pressure pump (ultra-high pressure hand pump from Enerpack, US, 5800 psi) to apply external pressure on the core. During the hydrogel injection, a 290 psi overburden pressure was applied, while the temperature was kept at $90{ }^{\circ} \mathrm{C}$. After placing the sandpack in the core holder at the desired temperature and pressure, the hydrogel was injected at a defined rate to prevent the destruction of the sandpack or fingering problems. Thereafter, the sandpack was kept at $90{ }^{\circ} \mathrm{C}$ until the gelation time of the hydrogel was reached based on the bottle test results.

\subsubsection{Compressive strength measurement}

To evaluate the performance of the sandpack consolidated with hydrogel, the compressive strength of the sandpack after hydrogel injection, as a method of mechanical strength tests, was determined. For this purpose, the sandpack treated with hydrogel was placed in the uniaxial compression testing machine (Heico Co., India) with 100 tons capacity. The pressure gauges on two upper and lower jaws showed the compressive values of each sandpack based on its strength.

\subsection{Scanning electron microscopy (SEM)}

The morphology of hydrogels was examined with a scanning electron microscope (Tescan-VEGA, Czech). Before morphology observation, the hydrogel samples were dried at $60{ }^{\circ} \mathrm{C}$ in an UN55 oven (Memmert, Germany) and were then gold-sputtered under vacuum prior to SEM examination.

\subsection{Thermal analysis}

Thermal stability indicates the ability of the hydrogel to survive the high temperature of the specific wells (Salimi 
Table 1 Gelation time of designed hydrogels at $90{ }^{\circ} \mathrm{C}$

\begin{tabular}{lcccc}
\hline Polymer concentration, ppm & \multicolumn{4}{c}{ Gelation time at various cross-linker/polymer weight ratios, $\mathrm{h}$} \\
\cline { 2 - 5 } & 0.5 & 0.2 & 0.1 & 0.05 \\
\hline 11,000 & 9 & 15 & 60 & 60 \\
9500 & 6 & 15 & 60 & 90 \\
7500 & 15 & 30 & 90 & No gelation \\
5500 & 90 & 70 & No gelation & No gelation \\
\hline
\end{tabular}
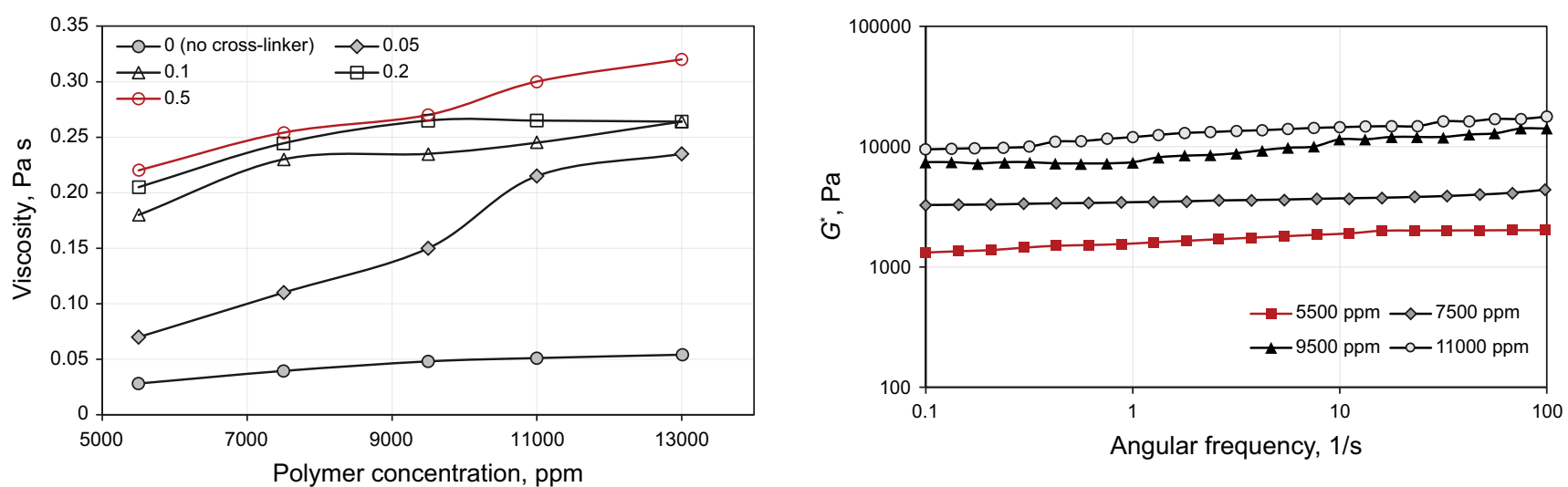

Fig. 4 Hydrogel viscosity versus polymer concentration at various cross-linker/polymer weight ratios

et al. 2014; Zhao et al. 2015). For this purpose, the thermal stability of hydrogel was measured by TGA using a Netzsch TGA 209 F1 (Germany) under a nitrogen atmosphere. A heating curve from 25 to $600{ }^{\circ} \mathrm{C}$ with a speed of $10{ }^{\circ} \mathrm{C} /$ min was set out. Based on the changing weight of the sample due to the increasing temperature (Rezakazemi et al. 2016, 2018), the thermal strength and its performance in porous media were evaluated.

\section{Results and discussion}

\subsection{Evaluation of hydrogel strength}

In order to qualitatively investigate the hydrogel structure and its suitable gelation time, experiments were designed based on two parameters: polymer concentration (5500-11,000 ppm) and cross-linker/polymer weight ratio $(0.05-0.5)$. The response of the hydrogel gelation time (the time required to form slightly deformable non-flowing gel (code H)) can be observed in Table 1.

To form a hydrogel, a minimum concentration of polymer and cross-linker is needed. However, only some samples could result in a hydrogel with suitable gelation and structural strength. In this study, the minimum polymer concentration was $5500 \mathrm{ppm}$. As is shown, hydrogel formed from $9500 \mathrm{ppm}$ polymer and 0.5 cross-linker/ polymer weight ratio had the shortest gelation time of $6 \mathrm{~h}$,
Fig. 5 Complex modulus as a function of frequency at different polymer concentrations and 0.5 cross-linker/polymer weight ratio

and the longest gelation time was about 4 days for the hydrogel which was formed at the conditions of the lowest polymer concentration $(5500 \mathrm{ppm})$ and the highest crosslinker/polymer weight ratio $(0.5)$. As a result, there was a wide variety in gelation time. Increasing polymer concentration and cross-linker/polymer weight ratio leads to a shorter gelation time. It seems that the hydrogel formed from $9500 \mathrm{ppm}$ polymer and 0.5 cross-linker/polymer weight ratio had the most economically suitable gelation time and composition.

To better define the gelation, the viscosity was also measured at a shear rate of $101 / \mathrm{s}$ at $90{ }^{\circ} \mathrm{C}$ for different hydrogels of the selected polymer concentrations and with and without cross-linker (Fig. 4). As is shown, the effect of polymer concentration on the viscosity of the sample without cross-linker was negligible, and this can be explained by the fact that no hydrogel was formed in the solution due to the lack of cross-linker, while for the other hydrogels, their viscosity values increased along with the polymer concentration and the cross-linker/polymer weight ratio. In other words, an increase in the viscosity of gelant solution confirmed the formation of a semisolid network of the hydrogel.

The complex modulus of the synthesized gel with a lifetime of 7 days was investigated to determine the hydrogel network strength. Figure 5 shows the complex dynamic modulus of hydrogels versus the frequency which was applied with the parallel-plate geometry. The results reveal that $G^{*}$ increased with an increase in polymer 
concentration. This indicates the higher strength of the hydrogel structure and also the higher resistance to the applied strain (Mousavi Moghadam et al. 2014). Moreover, the independent complex modulus to frequency represented the gelation of a 3D network in the hydrogel. As can be seen, there is only a slight difference between the complex modulus of two polymer concentrations 9500 and $11,000 \mathrm{ppm}$, so the $9500 \mathrm{ppm}$ was selected to the rest of the study.

\subsection{Effect of hydrogel injection on compressive strength}

The sandpack was evacuated by a vacuum pump and then saturated with synthesized formation water. Based on the volume of formation water injected into the sandpack, the pore volume $(\mathrm{PV})$ of the sandpack was calculated to be $30 \mathrm{~mL}$ (i.e., $1 \mathrm{PV}=30 \mathrm{~mL}$ ). Afterward, a hydrogel containing $9500 \mathrm{ppm}$ polymer and a cross-linker/polymer weight ratio of 0.5 was injected into the sandpack to consolidate and strengthen the sand grains. Moreover, a control sample for the following experiments was a sandpack without hydrogel injection. The compressive strength of the consolidated or treated sandpack was measured with a compression testing machine after its gelation (based on the bottle test results). As illustrated in Table 2, the ultimate compressive strength was improved by increasing the injection volume of hydrogel. However, in order to prevent the possible formation of filter cake during the injection process, $0.5 \mathrm{PV}$ of hydrogel was selected as the optimum volume which increased the compressive strength 15 times compared with the control sample.

\subsection{Effect of polymer concentration on compressive strength}

In this section, $0.5 \mathrm{PV}$ hydrogels of various polymer concentrations $(7500,9500$, and 11,000 ppm) were, respectively, injected into the sandpacks to investigate the effect of polymer concentration on compressive strength after gelation, while the cross-linker/polymer weight ratio was kept at 0.5 . A sandpack control sample was also prepared

Table 2 Compressive strength of the treated sandpack as a function of injection volume of hydrogel

\begin{tabular}{lll}
\hline $\begin{array}{l}\text { Hydrogel composition (polymer } \\
\text { concentration, cross-linker/polymer } \\
\text { weight ratio) }\end{array}$ & $\begin{array}{l}\text { Injection } \\
\text { volume, } \\
\text { PV }\end{array}$ & $\begin{array}{l}\text { Compressive } \\
\text { strength, psi }\end{array}$ \\
\hline 9500 ppm, 0.5 & 1.0 & 67.4 \\
9500 ppm, 0.5 & 0.5 & 30.2 \\
9500 ppm, 0.5 & 0.2 & 18.5 \\
0 ppm, 0 (control sample) & 0 & 2.2 \\
\hline
\end{tabular}

Table 3 Compressive strength of the treated sandpack as a function of polymer concentration

\begin{tabular}{lll}
\hline $\begin{array}{l}\text { Hydrogel composition (polymer } \\
\text { concentration, cross-linker/polymer } \\
\text { weight ratio) }\end{array}$ & $\begin{array}{l}\text { Injection } \\
\text { volume, } \\
\text { PV }\end{array}$ & $\begin{array}{l}\text { Compressive } \\
\text { strength, psi }\end{array}$ \\
\hline 11,000 ppm, 0.5 & 0.5 & 34.8 \\
9500 ppm, 0.5 & 0.5 & 30.1 \\
7500 ppm, 0.5 & 0.5 & 26.1 \\
0 ppm, 0 (control sample) & 0 & 2.2 \\
\hline
\end{tabular}

for a further comparison along with other sandpacks treated by hydrogels. Experimental results listed in Table 3 revealed that the compressive strength of the control sample before injecting the gel was less than $5 \mathrm{psi}$, while it increased to 26.1 and 30.1 psi after treated by hydrogel solutions of 7500 and $9500 \mathrm{ppm}$ polymer, respectively. In the same way, after being treated with the $11,000 \mathrm{ppm}$ polymer hydrogel, the sandpack compressive strength increased to about 34.8 psi. Therefore, it can be concluded that the sandpack compressive strength increased with the polymer concentration. This phenomenon can be explained by the fact that the higher the concentrations of polymer and cross-linker are, the thicker layers formed on the surface of sand grains and the stronger bonds formed among them and ultimately the higher compressive strength created.

Figure 6 shows SEM images of two hydrogel samples of a polymer concentration of 9500 and $7500 \mathrm{ppm}$ and a 0.5 weight ratio of cross-linker/polymer, respectively. As indicated in Fig. 6a, polymer chains were covalently bonded to the support and a three-dimensional network was formed by chemical cross-linking which ensured the structural strength of the hydrogel. However, in Fig. 6b aggregation of cross-linkers in the structure of hydrogel illustrated that at a low polymer concentration $(7500 \mathrm{ppm})$, an increase in cross-linker concentration had a negligible effect on networking or increase in subsequent hydrogel strength.

\subsection{Effect of cross-linker concentration on compressive strength}

0.5 PV hydrogels of various cross-linker/polymer weight ratios, $0.5,0.2$, and 0.1 were injected into the sandpack to investigate the effect of cross-linker concentration on the compressive strength, while the polymer concentration was kept at $9500 \mathrm{ppm}$. As observed from Table 4, when the hydrogel was injected into the sandpack at cross-linker/ polymer weight ratios of 0.1 and 0.2 , the compressive strength of the sandpack increased from 2.2 to about 10.2 and 30.1 psi, respectively. Furthermore, when the crosslinker/polymer ratio was 0.5 , the compressive strength 

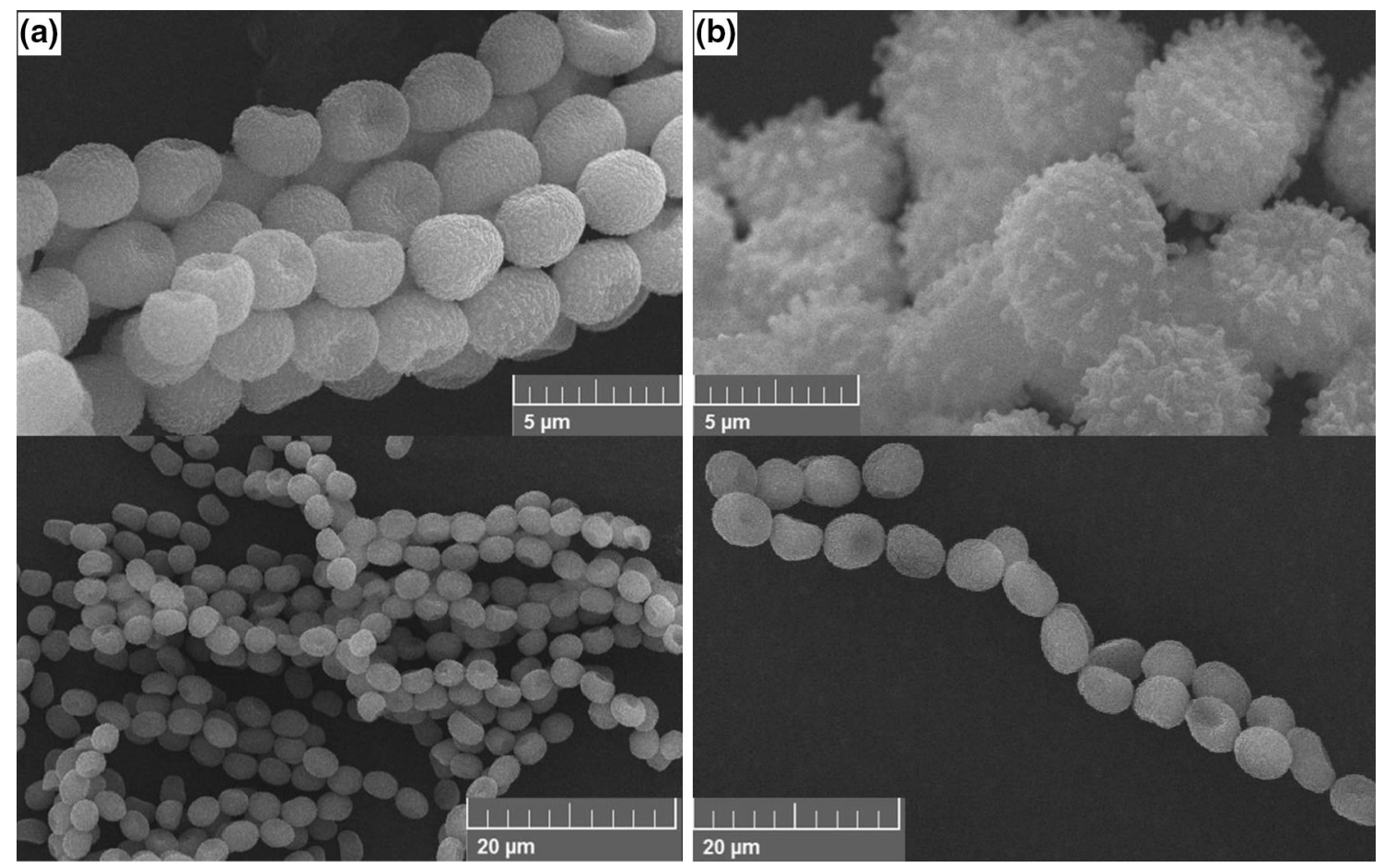

Fig. 6 SEM images of samples of hydrogel of polymer concentration of 9500 ppm (a) and 7500 ppm (b) (0.5 cross-linker/polymer weight ratio)

Table 4 Compressive strength of the treated sandpack as a function of cross-linker concentration

\begin{tabular}{lll}
\hline $\begin{array}{l}\text { Hydrogel composition (polymer } \\
\text { concentration, cross-linker/polymer } \\
\text { weight ratio) }\end{array}$ & $\begin{array}{l}\text { Injection } \\
\text { volume, } \\
\text { PV }\end{array}$ & $\begin{array}{l}\text { Compressive } \\
\text { strength, psi }\end{array}$ \\
\hline 9500 ppm, 0.5 & 0.5 & 47.9 \\
9500 ppm, 0.2 & 0.5 & 30.1 \\
9500 ppm, 0.1 & 0.5 & 10.2 \\
0 ppm, 0 (control sample) & 0 & 2.2 \\
\hline
\end{tabular}

increased to 47.9 psi, more than 20 times that of the sandpack control sample. This result showed that increasing the concentration of chromium triacetate (as a crosslinker) would improve the adsorption of hydrogel solution on the surface of sand grains (Wan et al. 2015), so that the hydrogel could generate stronger bonds among the sand grains. On the other hand, the hydrogel strength was increased by adding the cross-linker, which linked the sand grains with a more powerful intermolecular force.

To investigate the effect of cross-linker concentration on the microstructures of the hydrogel, the dynamic viscoelastic properties were examined by strain sweep tests with an oscillatory rheometer. As is known, when an increasing strain is applied at a constant angular frequency, the object may show a constant, strain-independent response below a threshold value. The corresponding strain interval is called the linear viscoelastic region (Adewunmi

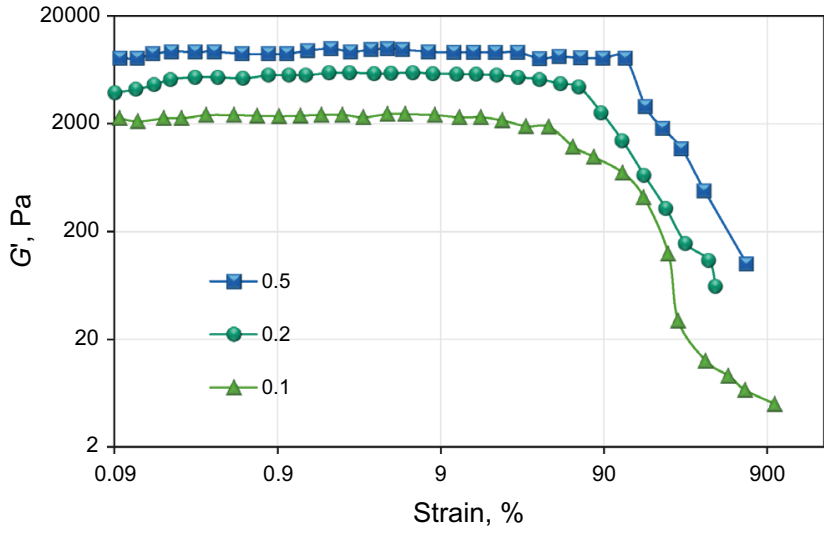

Fig. 7 Strain dependence of the storage modulus at $90{ }^{\circ} \mathrm{C}$ for hydrogels with a constant polymer concentration of $9500 \mathrm{ppm}$ and at different cross-linker/polymer weight ratios

et al. 2017). A further increase in strain usually results in a drastic decrease in moduli (Gyarmati et al. 2017). Figure 7 shows the elastic modulus $\left(G^{\prime}\right)$ of the hydrogel (with a constant polymer concentration of $9500 \mathrm{ppm}$ ) as a function of strain (dynamic strain sweep test) at different crosslinker/polymer weight ratios. Experimental results show that the $G^{\prime}$ of the hydrogel with a cross-linker/polymer weight ratio of 0.5 increased substantially. Moreover, hydrogel with a higher cross-linker concentration can keep its viscoelastic behavior in a larger strain value: strain of $122 \%$ at weight ratio of 0.5 as compared to $63 \%$ and $42 \%$ for weight ratio of 0.2 and 0.1 , respectively. 


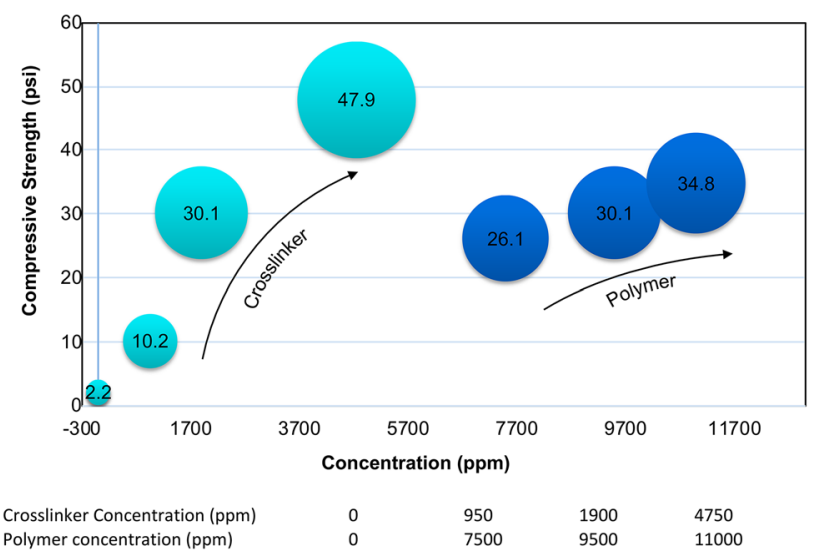

Fig. 8 Comparison of the effects of polymer and cross-linker concentrations on the compressive strength of sandpack treated by hydrogels

Figure 8 shows the effect of polymer and cross-linker concentrations on the compressive strength. As can be seen, the compressive strength is more sensitive to the variation of cross-linker concentration so the maximum compressive strength was obtained at the higher crosslinker concentration. Therefore, the cross-linker concentration was selected in the range of $0.1,0.2$, and 0.5 at a constant polymer concentration of $9500 \mathrm{ppm}$ to achieve the maximum compressive strength (47.9 psi).

\subsection{Effect of electrolyte solution on hydrogel strength}

In order to investigate the effect of electrolyte solution on viscoelastic properties of the hydrogel, the loss factor of the hydrogel in the presence of mono and divalent cations namely from $\mathrm{NaCl}, \mathrm{KCl}, \mathrm{MgCl}_{2}$, and $\mathrm{CaCl}_{2}$, which are the most available cations in the reservoir formation water, was studied at a fixed total salinity of 10,000 ppm (Fig. 9).

Based on the strain sweep test, as the strain increased to a certain value, called as the critical strain, the loss factor was negligible. However, a further increase in the strain beyond the critical value caused the loss factor to increase suddenly $(\tan \delta>1$ ). Under this condition, the storage modulus is the lowest compared to the loss modulus. In fact, a viscoelastic transition occurs from solid state to liquid state and the hydrogel network breaks down (Osswald and Rudolph 2015). In other words, the hydrogel retains its viscoelastic properties in an electrolyte environment before getting close to its critical strain. According to the results, the presence of mono and divalent cations reduced the hydrogel strength, which is in line with the results of Karimi et al. (2016). However, a close look at the results shows that the negative impact of calcium cation was more significant. In the presence of an electrolyte solution, mono and divalent ions act like a cross-linker competing with chromium ions, which leads to gel networking reduction and also a decline in gel strength (Salimi et al. 2014; Wan et al. 2015). It should be noted that divalent cations can bond carboxylate groups which can increase the syneresis and reduce the elasticity of the hydrogel structure. As a result, the critical strain in which the hydrogel lost its viscoelastic properties was obtained $1010 \%$ in distilled water, $862 \%$ in $\mathrm{KCl}, 493 \%$ in $\mathrm{NaCl}, 336 \%$ in $\mathrm{MgCl}_{2}$, and $201 \%$ in $\mathrm{CaCl}_{2}$.

\subsection{Effect of temperature on hydrogel strength}

The thermal properties of the hydrogels were also investigated using thermogravimetric analysis. Figure 10

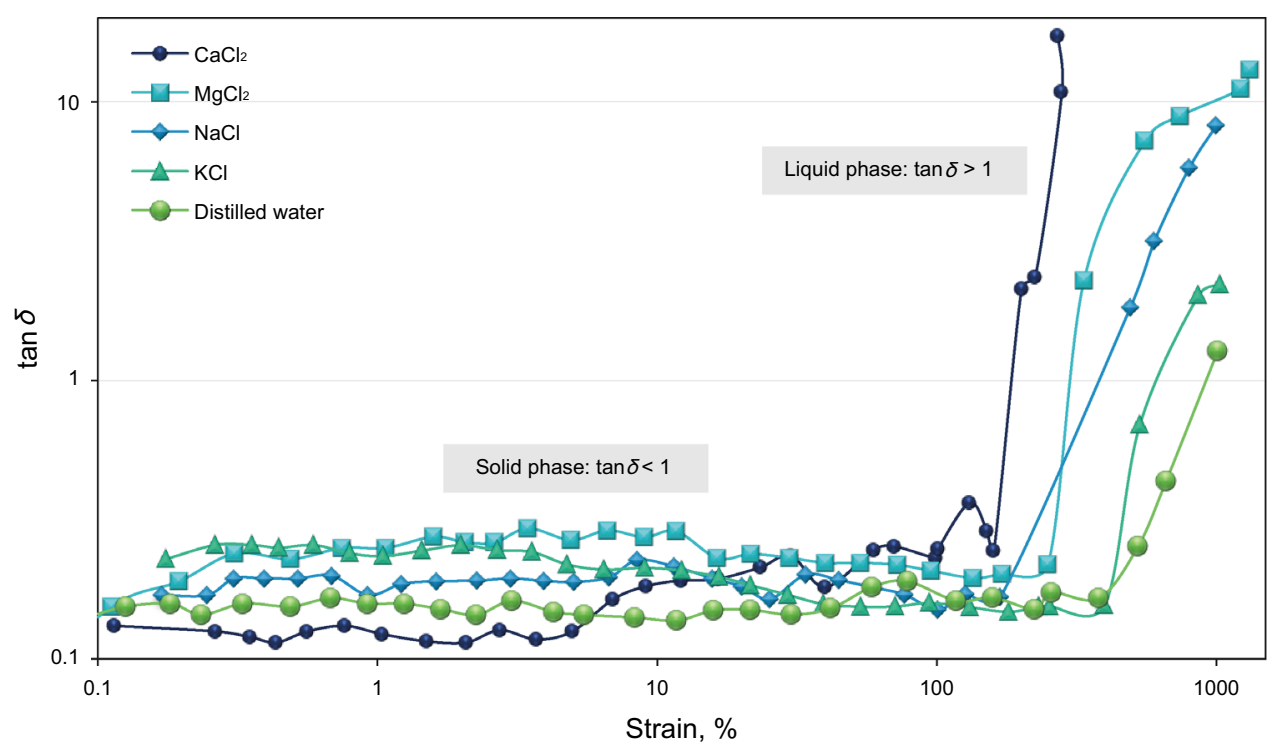

Fig. 9 Viscoelastic behavior of hydrogels in distilled water and 10,000 ppm electrolyte solutions at $90{ }^{\circ} \mathrm{C}$ 


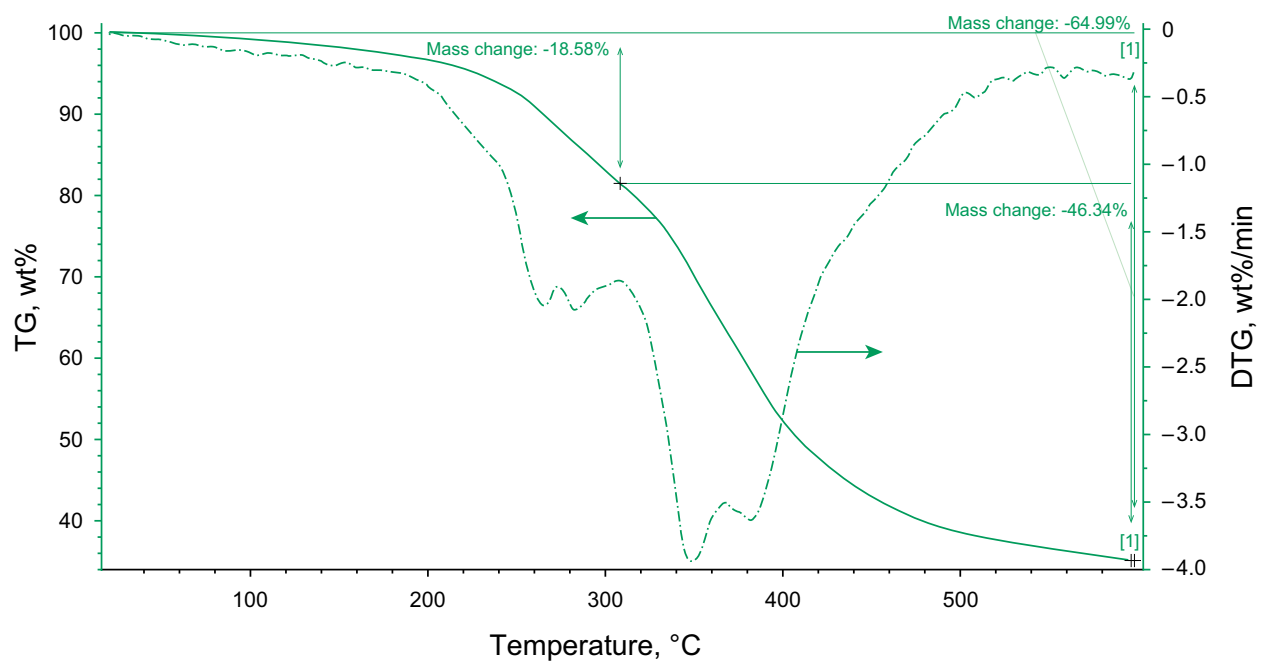

Fig. 10 TGA and DTG curves of the hydrogel containing $9500 \mathrm{ppm}$ polymer and 0.5 polymer/cross-linker weight ratio

illustrates the TGA and DTG curves of the hydrogel (9500 ppm polymer, polymer/cross-linker weight ratio of $0.5)$. The TGA profile showed the weight loss in two distinct stages: The first weight loss of about $18.5 \%$ was due to the release of typical strong hydrogen bonded water at around $175{ }^{\circ} \mathrm{C}$ (initial decomposition temperature, IDT), and the second weight loss of about $46 \%$ was due to the destruction of hydrogel from 300 to $600{ }^{\circ} \mathrm{C}$ (final decomposition temperature, FDT) (Zohuriaan and Shokrolahi 2004). The second stage corresponds to the thermal and oxidative decomposition of hydrogel and also vaporization and elimination of volatile products with decomposition and depolymerization of the hydrogel (Salimi et al. 2014). Accordingly, the total weight loss of the hydrogel was $65 \%$ at around $600{ }^{\circ} \mathrm{C}$. Thus, one can infer that the designed hydrogel retains its structure and strength at $90{ }^{\circ} \mathrm{C}$ which is the selected temperature of this study and also the typical temperature of Iranian oil reservoirs.

\section{Conclusions}

In this study, the performance of polyacrylamide/chromium triacetate hydrogel was investigated to control sand production. This was performed by injecting the hydrogel through a synthetic sandpack at $90{ }^{\circ} \mathrm{C}$ and measuring compressive strength to ascertain the capability of hydrogel to consolidate sand grains and restrict their movement during the production process. The effect of polymer and cross-linker concentrations, temperature, and presence of mono and divalent cations on the rheological behavior of the hydrogel was also investigated. Accordingly, the following conclusions have been drawn.
1. The bottle test results indicated that a strong gel network was developed in the presence of a crosslinker. Increases in polymer and cross-linker concentrations intensified the hydrogel strength.

2. The compression tests showed that the hydrogel was capable of increasing the compressive strength of sandpacks, so it can be recommended to be used as a strengthening agent.

3. The injection volume of the hydrogel could also affect the compressive strength of sandpacks. A 0.5 PV injection of hydrogel (with $9500 \mathrm{ppm}$ polymer and 0.5 polymer/cross-linker weight ratio) could increase the compressive strength of the sandpack up to $30 \mathrm{psi}$.

4. The polymer concentration directly affected the compressive strength by network formation. So that increasing the polymer concentration led to an increase in the compressive strength as well as the total stability. Likewise, the compressive strength was also improved by increasing the polymer/cross-linker weight ratio. Consequently, a comparison of the effect of polymer and cross-linker concentrations on the compressive strength indicated that the polymer/crosslinker weight ratio had the main effect in increasing the compressive strength of the sandpack (up to $48 \mathrm{psi}$ ).

5. Hydrogel with a higher proportion of cross-linker can retain its viscoelastic properties against the strain without any deforming. So, hydrogel with a crosslinker/polymer weight ratio of 0.5 lost its viscoelastic behavior at the maximum strain of $122 \%$, and with a ratio of 0.1 lost its viscoelastic behavior at the minimum strain of $42 \%$.

6. The presence of ions in formation water affected the hydrogel structure with a critical strain value for each electrolyte solution. Overall, the hydrogel containing 
$9500 \mathrm{ppm}$ polymer and with a polymer/cross-linker weight ratio of 0.5 retained its strength until $1010 \%$ strain as the maximum for distilled water and until $201 \%$ strain as the minimum one for $\mathrm{CaCl}_{2}$. Besides, divalent ions reduced the hydrogel strength more compared to monovalent ions.

7. TGA analysis showed that the weight loss of the hydrogels occurred in two different stages: initial decomposition at $175{ }^{\circ} \mathrm{C}$ with a weight loss of $18.5 \%$ and final decomposition at $600{ }^{\circ} \mathrm{C}$ with a weight loss of $46 \%$.

Acknowledgements The authors would like to acknowledge the support of the Iran National Science Foundation (INSF) with Project No. of 95849122 of this study.

Open Access This article is distributed under the terms of the Creative Commons Attribution 4.0 International License (http://creative commons.org/licenses/by/4.0/), which permits unrestricted use, distribution, and reproduction in any medium, provided you give appropriate credit to the original author(s) and the source, provide a link to the Creative Commons license, and indicate if changes were made.

\section{References}

Adewunmi AA, Ismail S, Sultan AS, Ahmad Z. Performance of fly ash based polymer gels for water reduction in enhanced oil recovery: gelation kinetics and dynamic rheological studies. Korean J Chem Eng. 2017;34(6):1638-50. https://doi.org/10. 1007/s11814-017-0071-8.

Aggour MA, Abu-Khamsin SA, Osman E-SA. Investigation of in situ low-temperature oxidation as a viable sand consolidation technique. J Pet Sci Eng. 2004;42(2-4):107-20. https://doi.org/ 10.1016/j.petrol.2003.12.004.

Akhlaghi Amiri HA, Hamouda AA. Pore-scale modeling of nonisothermal two phase flow in 2D porous media: influences of viscosity, capillarity, wettability and heterogeneity. Int J Multiph Flow. 2014;61:14-27. https://doi.org/10.1016/j.ijmultiphaseflow. 2014.01.001.

Baghban Salehi M, Vasheghani-Farahani E, Vafaie Sefti M, Mousavi Moghadam A, Naderi H. Rheological and transport properties of sulfonated polyacrylamide hydrogels for water shutoff in porous media. Polym Adv Technol. 2014;25(4):396-405. https://doi. org/10.1002/pat.3254.

Bai B, Zhou J, Yin M. A comprehensive review of polyacrylamide polymer gels for conformance control. Pet Explor Dev. 2015;42(4):525-32. https://doi.org/10.1016/s1876-3804(15) 30045-8.

Bellarby J. Well completion design. Amsterdam: Elsevier; 2009.

Bravo MC, Araujo M. Analysis of the unconventional behavior of oil relative permeability during depletion tests of gas-saturated heavy oils. Int J Multiph Flow. 2008;34(5):447-60. https://doi. org/10.1016/j.ijmultiphaseflow.2007.11.003.

Cholet H. Well production practical handbook. TECHNIP ed. Paris: Institut français du pétrole; 2000.

El-Sayed A-AH, Al-Awad MN, Al-Homadhi E. Two new chemical components for sand consolidation techniques. In: PE Middle East Oil Show, 17-20 March, Manama, Bahrain; 2001. https:// doi.org/10.2118/68225-MS
Fattahpour V, Moosavi M, Mehranpour M. An experimental investigation on the effect of grain size on oil-well sand production. Pet Sci. 2012;9(3):343-53. https://doi.org/10.1007/s12182-0120218-5.

Gholami R, Aadnoy B, Rasouli V, Fakhari N. An analytical model to predict the volume of sand during drilling and production. J Rock Mech Geotech Eng. 2016;8(4):521-32. https://doi.org/10. 1016/j.jrmge.2016.01.002.

Gyarmati B, Szilágyi BÁ, Szilágyi A. Reversible interactions in selfhealing and shape memory hydrogels. Eur Polymer J. 2017. https://doi.org/10.1016/j.eurpolymj.2017.05.020.

Ikporo B, Sylvester O. Effect of sand invasion on oil well production: a case study of Garon field in the Niger Delta. Int J Eng Sci. 2015;4(5):64-72.

Isehunwa SO, Olanrewaju O. A simple analytical model for predicting sand production in a Niger Delta Oil Field. Int $\mathbf{J}$ Eng Sci Technol. 2010;2(9):4379-87.

Karimi S, Esmaeilzadeh F, Mowla D. Identification and selection of a stable gel polymer to control or reduce water production in gas condensate fields. J Nat Gas Sci Eng. 2014;21:940-50. https:// doi.org/10.1016/j.jngse.2014.10.026.

Karimi S, Kazemi S, Kazemi N. Syneresis measurement of the HPAM-Cr(III) gel polymer at different conditions: an experimental investigation. J Nat Gas Sci Eng. 2016;34:1027-33. https://doi.org/10.1016/j.jngse.2016.08.011.

Kotlar HK, Haavind F, Springer M, Bekkelund SS, Torsaeter O. A new concept of chemical sand consolidation: from research idea to field application. In: SPE annual technical conference and exhibition, 9-12 October 2005, Dallas, Texas. https://doi.org/10. 2118/95723-MS.

Kotlar HK, Moen A, Haavind F, Strom S. Field experience with chemical sand consolidation as a remedial sand control option. In: Offshore technology conference, 5-8 May, Houston, Texas, USA; 2008. https://doi.org/10.4043/19417-MS.

Li DX, Zhang L, Liu YM, et al. $\mathrm{CO}_{2}$-triggered gelation for mobility control and channeling blocking during $\mathrm{CO}_{2}$ flooding processes. Pet Sci. 2016;13(2):247-58. https://doi.org/10.1007/s12182-0160090-9.

Li X, Song X, Yue X, Hou J, Fang L, Zhang H. Effects of shear fracture on in-depth profile modification of weak gels. Pet Sci. 2007;4(1):55-60. https://doi.org/10.1007/BF03186574.

Liu J, Seright RS. Rheology of gels used for conformance control in fractures. In: SPE/DOE improved oil recovery symposium, 3-5 April, Tulsa, Oklahoma, USA; 2000. https://doi.org/10.2118/ 59318-MS.

Maduabuchi OF, Appah D, Okoro ES. Relative study of internal gravel packing and chemical sand consolidation: sand control techniques of Niger Delta wells. Am J Eng Res. 2017;6(5):261-8.

Marfo SA, Appah D, Joel OF, Ofori-Sarpong G. Sand consolidation operations, challenges and remedy. In: Annual international conference and exhibition, 4-6 August, Lagos, Nigeria; 2015. https://doi.org/10.2118/178306-MS.

Mishra S, Ojha K. Application of an improvised inorganic-organic chemical mixture to consolidate loose sand formations in oil fields. J Pet Sci Eng. 2016a;137:1-9. https://doi.org/10.1016/j. petrol.2015.11.008.

Mishra S, Ojha K. Nanoparticle induced chemical system for consolidating loosely bound sand formations in oil fields. J Pet Sci Eng. 2016b;147:15-23. https://doi.org/10.1016/j.petrol.2016. 05.005 .

Mousavi Moghadam A, Vafaie Sefti M, Baghban Salehi M, Naderi H. Bulk and rheological properties of polyacrylamide hydrogels for water shutoff treatment. Korean J Chem Eng. 2014;31(3):532-9. https://doi.org/10.1007/s11814-013-0242-1. 
Osswald TA, Rudolph N. Polymer rheology: fundamentals and applications. Munich: Hanser Publications; 2015.

Pedersen S, Durdevic P, Yang Z. Challenges in slug modeling and control for offshore oil and gas productions: a review study. Int J Multiph Flow. 2017;88:270-84. https://doi.org/10.1016/j.ijmulti phaseflow.2016.07.018.

Rezakazemi M, Vatani A, Mohammadi T. Synthesis and gas transport properties of crosslinked poly(dimethylsiloxane) nanocomposite membranes using octatrimethylsiloxy POSS nanoparticles. J Nat Gas Sci Eng. 2016;30:10-8. https://doi.org/10.1016/j.jngse.2016. 01.033 .

Rezakazemi M, Sadrzadeh M, Matsuura T. Thermally stable polymers for advanced high-performance gas separation membranes. Prog Energy Combust Sci. 2018;66:1-41. https://doi.org/10.1016/j. pecs.2017.11.002.

Salimi F, Sefti MV, Jarrahian K, Rafipoor M, Ghorashi SS. Preparation and investigation of the physical and chemical properties of clay-based polyacrylamide/Cr(III) hydrogels as a water shut-off agent in oil reservoirs. Korean $\mathrm{J}$ Chem Eng. 2014;31(6):986-93. https://doi.org/10.1007/s11814-014-0023-5.

Singh P, van Petegem R. A novel chemical sand and fines control using zeta potential altering chemistry and placement techniques. In: IPTC 17614 presented at international petroleum technology conference; 2014/1/19/; Doha, Qatar. IPTC: International Petroleum Technology Conference; 2014.

Sydansk RD. A new conformance-improvement-treatment chromium(iii) gel technology. In: SPE enhanced oil recovery symposium, 16-21 April, Tulsa, Oklahoma; 1988. https://doi.org/10. 2118/17329-MS
Sydansk RD. Sand consolidation treatment for a hydrocarbon production well bore using an overdisplacement fluid. U.S. Patent 5,082,057. 1992.

Sydansk RD, Argabright PA. Conformance improvement in a subterranean hydrocarbon bearing formation using a polymer gel. U.S. Patent 4,683,949. 1987.

Villesca J, Hurst G, Bern PA, Nguyen PD, Rickman RD, Dusterhoft RG. Development and field applications of an aqueous-based consolidation system for remediation of solids production. In: Offshore technology conference, 3-6 May, Houston, Texas, USA; 2010. https://doi.org/10.4043/20970-MS.

Wan T, Cheng W, Zhou Z, Xu M, Zou C, Li R. Influence of crosslinker amount on swelling and gel properties of hectorite/ poly(acrylamide/itaconic acid) nanocomposite hydrogels. Korean J Chem Eng. 2015;32(7):1434-9. https://doi.org/10.1007/ s11814-014-0313-y.

Wasnik AS, Mete SV, Ghosh B. Application of resin system for sand consolidation, mud loss control \& channel repairing. In: SPE international thermal operations and heavy oil symposium, 1-3 November, Calgary, Alberta, Canada; 2005. https://doi.org/10. 2118/97771-MS.

Yanovsky YG. Polymer rheology: theory and practice. 1st ed. Dordrecht: Springer Science and Business Media; 1993.

Zhao G, Dai C, Chen A, Yan Z, Zhao M. Experimental study and application of gels formed by nonionic polyacrylamide and phenolic resin for in-depth profile control. J Pet Sci Eng. 2015;135:552-60. https://doi.org/10.1016/j.petrol.2015.10.020.

Zohuriaan MJ, Shokrolahi F. Thermal studies on natural and modified gums. Polym Test. 2004;23(5):575-9. https://doi.org/10.1016/j. polymertesting.2003.11.001. 